Hydrol. Earth Syst. Sci. Discuss., 6, 589-625, 2009 www.hydrol-earth-syst-sci-discuss.net/6/589/2009/ (C) Author(s) 2009. This work is distributed under the Creative Commons Attribution 3.0 License.

\title{
Hydroperiod and hydraulic loading for treatment potential in urban tidal wetlands
}

\author{
T. T. Eaton and C. Yi \\ School of Earth and Environmental Sciences, Queens College CUNY, 65-30 Kissena Blvd, \\ Flushing, NY 11367, USA \\ Received: 20 October 2008 - Accepted: 26 October 2008 - Published: 30 January 2009 \\ Correspondence to: T. T. Eaton (timothy.eaton@qc.cuny.edu) \\ Published by Copernicus Publications on behalf of the European Geosciences Union.
}

\begin{abstract}
Conventional methods of estimating water quality improvement due to wetland treatment are not well suited to the dynamic water level and wetted area fluctuations observed in coastal settings. We present a new method to quantify hydroperiod and 5 hydraulic loading at different elevations in a coastal wetland profile in which the principal inflows and outflows are due to tides. We apply our method to an urban coastal setting (part of the New York-New Jersey Harbor Estuary) where a major water quality problem persists due to fecal coliform contamination from combined sewer overflow (CSO) discharges. Based on three types of simplified hydrograph, we show how such 10 an approach and conceptual model of a terraced tidal wetland with constant mean slope can be used to assess hydrologic constraints for wetland vegetation species and the potential treatment effectiveness for adjacent impaired coastal waters. Resulting hydroperiods and hydraulic loading values decrease approximately exponentially with elevation along the wetland profile with considerable variation in overall slope depend-

15 ing on the hydrograph pattern. Application of a first-order contamination reduction model using our calculated hydraulic loadings indicates that such tidal treatment wetlands could reduce average fecal coliform concentrations in the range of $27 \%$ to $94 \%$ depending on the pattern of water level fluctuation, wetland surface elevation and vegetation density. Our analysis shows the performance potential for tidal wetlands to treat adjacent coastal waters. Restoration of existing salt marshes, and construction of new tidal wetlands would therefore be a promising part of an ecohydrologic strategy to improve water quality in contaminated urban coastal settings like the New York-New Jersey Harbor Estuary.
\end{abstract}

\section{Introduction}

Hydrology is commonly cited as the most important control on wetland ecosystems, creating the hypoxic conditions necessary for hydric soil development, and the stressed 
conditions to which specialized vegetation is adapted (Mitsch and Gosselink, 2007). Water level fluctuations are measured to quantify wetland hydrology, and the length of time that a wetland or part thereof is submerged to varying depths is referred to as the hydroperiod (Nuttle, 1997; Kadlec and Knight, 1996; Mitsch and Gosselink,

5 2007). Depth of inundation is an important component of wetland hydrology, controlling the survival of different vegetation species and differentiating habitat for wetland fauna (Kadlec and Knight, 1996). The pulsation of the water regime over time (Odum et al., 1995) is recognized as one of the factors promoting wetland biological productivity, especially for coastal and saltmarsh systems (Mitsch and Gosselink, 2007). Tidal

10 fluctuations have also been demonstrated to enhance aerobic conditions for plant root respiration ( $\mathrm{Li}$ et al., 2005). However, for estimating how well natural and constructed wetlands reduce contaminant levels in the water that flows through them, conventional methods of calculating hydraulic loading (Kadlec and Wallace, 2008; Kadlec and Knight, 1996) assume relatively constant water depths and wetted areas over time, 15 which is not typical of the dynamic hydrology found in tidal wetlands.

There is a great need to quantify the hydrology of urban tidal marshes because so much urban wetland has already been lost to development. New techniques to assess the benefits of urban tidal wetlands for adjacent coastal waters highlight the ecological functions of such wetlands and promote stewardship and restoration of remaining 20 urban marshes. In coastal areas where much tidal marsh has already been lost, successful restoration of these critically endangered coastal habitats, as mandated under the US government policy of "no net loss", depends on better understanding of natural wetlands hydroperiod, and better ways of quantifying wetland hydraulic regime (Montalto and Steenhuis, 2004).

25 Ecohydrology is a relatively new field that applies the interaction between hydrology and biota to address and manage stresses caused by human impacts on water resources (Zalewski, 2000, 2002). In many urbanized estuaries and coastal zones, engineering and technological solutions to water treatment are reaching their capacity, and coupling of ecology and hydrology has been proposed as a more sustainable strat-

591

egy for restoring and enhancing natural processes to combat the impacts of nutrients and pollutants (Wolanski et al., 2004; Vokral et al., 2003). Wetlands are increasingly used for wastewater treatment around the world (Song et al., 2006; Cooper, 2005; Kadlec and Knight, 1996; Kadlec and Wallace, 2008), but more attention has focused 5 on inland flow-through freshwater systems than on coastal tidal systems. Treatment effectiveness is directly related to the length of time that water is present in wetlands (hydroperiod) and hydraulic loading (inflow rate per wetland area), which result in a firstorder rate-limited decrease in contaminant concentrations, as is well documented by data on common wastewater constituents (Kadlec and Knight, 1996; Waterman and 10 Brown, 1994). More recently, constructed systems are being developed with artificial "tidal" fluctuations (Song et al., 2006), since such cyclical hydraulic loadings have been demonstrated to improve treatment efficacy (Sun et al., 1999a, b) as well as reduce the likelihood of media clogging in subsurface flow (Langergraber et al., 2003; Kadlec and Knight, 1996; Kadlec and Watson, 1993). Recirculation of wastewater through treat15 ment beds is also being investigated (Sun et al., 2003; Zhao et al., 2004), whereas similar processes in natural coastal wetlands have not received much study.

The many different configurations of natural and constructed wetlands create a variety of hydrologic regimes with both unidirectional (standard treatment wetlands, flowthrough natural wetlands) and bidirectional flow (coastal, riverine wetlands). In the

20 latter cases, the concepts of hydroperiod and hydraulic loading are not always clear, and have not commonly been quantified. Some authors have extended the hydroperiod concept to include subsurface water (Hunt et al., 1999), the time during which the soil is saturated to the land surface. Plots of water level vs. time have often been used to distinguish between different classes of natural wetlands (Mitsch and Gosselink,

25 2007) and standard depth-duration and stage-storage analyses have been applied to treatment wetland systems (Kadlec and Knight, 1996). Another measure of hydraulic regime is the fluctuation of wetted area over time, which has been described for wetlands in arid climates (Kadlec and Knight, 1996), but the treatment implications have not been explored for tidal wetlands. These measures do not capture all the variabil- 
ity in the hydroperiod, in particular the frequency of continuous lengths of time over which water is present, or the seasonal variation in spatial distribution of ponded water (Boswell and Olyphant, 2007). Hunt et al. (1999) proposed a type of analysis, the root-zone residence time, that addresses the continuity of saturation in the subsurface.

5 Nuttle (1997) and Long and Nestler (1996) used harmonic analysis to investigate the effects of changes of hydroperiod on wetland ecosystems. However, few quantitative analyse have been presented that permit comparison of the spatial distribution of both water depth and flooding duration within and among wetlands, or enable prediction of hydroperiod or assessment of hydraulic loading. In constructed treatment wetlands,

10 hydroperiod prediction is needed to ensure successful vegetation development and assessment of hydraulic loading is needed to plan the appropriate wetland size needed, and project treatment effectiveness.

Here, we propose, using a conceptual model of a tidal wetland, a new method of quantifying hydroperiod and hydraulic loading based on analysis of the variation in wa-

15 ter levels over time. For the purposes of this work, we define hydroperiod to include the proportion of time over which inundation occurs as well as the depth of inundation, so that it can be characterized for any point in the wetland where water level measurements are made. While our conceptual model is developed for a coastal setting, where tidal forcing controls the hydroperiod, our method would also be applicable to settings in which the hydroperiod is not as regular, or where fluctuation occurs over much longer time periods. We develop our calculations in general, and illustrate them using examples of three hypothetical but progressively more realistic representations of water level fluctuation in a $24 \mathrm{~h}$ period. We also show how the resulting spatial distribution of hydroperiod and assessment of hydraulic loading can be used to design a constructed or restored tidal wetland to treat adjacent coastal waters of poor quality.

\section{Background and conceptual model}

\subsection{Urban setting}

New York City, like many urban areas that are located in major estuaries (Jeng et al., 2005; Garcia-Barcina et al., 2006), has a persistent problem with water quality in the 5 adjacent New York-New Jersey Harbor Estuary, because of the numerous sources of non-point source runoff, wastewater treatment and combined sewer overflow (CSO) discharges. Although considerable progress has been made in the last 25 years in overall water quality (Steinberg et al., 2004), the capacity of wastewater treatment plants (WWTPs) is exceeded during wet weather events, necessitating direct sewage discharge to the coastal waters. More stringent discharge regulations imposed by the US Environmental Protection Agency have resulted in the development by the New York City Department of Environmental Protection (NYCDEP) of greater infrastructure capacity to contain these sources of pathogenic contamination (NYCIBO, 2004). However, small embayments in the Harbor Estuary, such as Flushing Bay (Fig. 1), where 15 there are numerous CSO outfalls (Fugate and Chant, 2006; Eaton, 2007), are still not in compliance with minimal standards for recreational contact, and Flushing Bay is listed on the 2004 New York State Section 303(d) list of impaired water bodies. Weekly monitoring in the summer of 2006 showed that total coliform contamination is routinely well in excess of $500 \mathrm{CFU} / 100 \mathrm{~mL}$ (Eaton, unpublished data), and more re-

20 cent weekly sampling at the creek end of the Bay in Fall 2006 and Spring/Fall 2007 has shown mean levels of fecal coliform bacteria over $12000 \mathrm{CFU} / 100 \mathrm{~mL}$, mean E-coli over $800 \mathrm{CFU} / 100 \mathrm{~mL}$ and mean enterococci in the 10 s to $100 \mathrm{~s}$ CFU/100 mL (Dhar, unpublished data).

Constructed and restored wetlands are already being employed in one borough of 25 New York City to treat stormwater discharge with the Staten Island Bluebelt program, a system that integrates stormwater best management practices (BMPs) with the preexisting natural hydrology of creeks and restored small freshwater wetlands (Vokral et al., 2003). While source control of CSO discharges and changing relative ground- 
water/surface water discharges (Eaton, 2007) are likely to have a noticeable positive impact on coastal water quality, restoration of tidal wetlands in the New York City area remains an underexploited opportunity for additional water quality improvement. Although wetlands can certainly be a source for low levels of pathogens (Grant et al.,

5 2001), the magnitude of the existing water quality problem in parts of the New YorkNew Jersey Harbor Estuary like Flushing Bay indicates that tidal wetland restoration can be an important component to an overall water quality improvement strategy. The current administration of Mayor Bloomberg has made wetlands restoration and preservation a priority of his plan $(\mathrm{OEC}, 2007)$ to improve environmental quality over the next

10 twenty-five years. As a result, a comprehensive inventory of city-owned property containing wetlands, and transfer of those parcels to NYC Dept. of Parks and Recreation for protection and restoration, is currently underway (NYCWTTF, 2007). Experience in other major urban estuaries (Simenstad et al., 2005) has shown that tidal wetland restoration is viable even in the most industrialized settings.

\section{$15 \quad 2.2$ Conceptual model}

Tidal wetlands restoration or construction for water treatment purposes has not commonly been attempted, perhaps because of the hydrologic complexity described earlier. Even ecological restoration of these critically endangered habitats has lagged behind that of inland, freshwater settings (Dahl, 2006). However, recent efforts have met with some success (Havens et al., 2002; Zedler and Callaway, 2000). Here, for the purposes of our analysis, we present a design for a simplified tidal wetland that is generic enough to be adapted to numerous coastal settings, including the New York-New Jersey Harbor Estuary. Because of its small size, this simplified conceptual model does not include tidal channels, an important component of natural tidal wetlands (Zeff, 1999;

25 Marani et al., 2003, 2002). However, the analysis presented here could be applied to any small area or transect with a reasonably uniform slope immediately adjacent to a tidal channel.

Consider a rectangular area parallel to the coastline and extending $24 \mathrm{~m}$ inland from 595

the low water mark (Fig. 2). The wetland vegetation and hydrologic conditions are assumed to be uniform in the direction parallel to the coastline. The tidal range dimension of the wetland is merely chosen for convenience and could be scaled to any tidal range such that the elevations of the lower and upper edges of the wetland match 5 the lowest and highest tidal levels (as defined appropriately for each specific setting), respectively. Here, we also specify that the tidal range is $1 \mathrm{~m}$ for convenience in scaling to other settings. The wetland bed slope is assumed constant (0.04) and this would likely be a mean slope of a system of terraces at different elevations (Feagin and Wu, 2006) such as are found in many natural coastal wetlands. Water level fluctuations with the tide can be plotted over a $24 \mathrm{~h}$ time-period such that the same vertical scale can be used for both water depth and surface elevation at any point on the wetland profile (Fig. 3). Water depth $h$ is therefore directly related to elevation $\left(h_{i}=h_{0}-z_{i}\right.$, see Fig. 2). Although the typical diurnal tidal fluctuation has a period of $12.42 \mathrm{~h}$, such that there are two high tides per day that advance through time, we also assume here for convenience that the tidal period is exactly $12 \mathrm{~h}$, such that high tide occurs at 06:00 and 18:00 every day. This simplification allows us to show the correspondence between our analytical calculations and numerical results in a straightforward way over the period of a day. More complex mathematical models of the tide are possible (Xun et al., 2006), but are not necessary to our analysis.

20 We note that because of the geometry of this conceptual model, with a constant mean slope and periodic tidal inflow, there is a unique hydroperiod $\Omega$ for any elevation along the wetland profile because the water depth and wetted area change continuously in time and space $(h=f(x, t), A=f(x, t))$. Therefore, it is not appropriate to assess treatment effectiveness from hydraulic loading based on assumed steady-state or 25 "average" fluxes of water inflow or wetted area as is commonly done for flow-through treatment wetlands (Kadlec and Knight, 1996; Kadlec and Wallace, 2008). For the purposes of this work, we are interested in the hydroperiod at four different locations in the wetland, in the exact center of each of four $6 \mathrm{~m}$ wide panels (L1-L4) parallel to the shoreline (Fig. 2). Equivalently, each of these four locations represents terraces of 
dimension $6 \mathrm{~m}$ perpendicular to the shoreline, in a stairstep wetland elevation profile shown with horizontal lines. The depth of water at each of these locations reaches a maximum at 06:00 and 18:00 every day as the high tide completely covers the wetland area. Due to the constant mean slope of the wetland profile, water level fluctuation

5 at each location is simply a vertical translation of the water level plot over time. The resulting wetted area at each time for each of the hydrograph types is a linear but continuously varying function of the water level $h$ and the sine of the mean wetland bedslope. The diurnal tidal fluctuation is first simplified to a linear sawtooth pattern (Fig. 3a), then represented as a more realistic sine function (Fig. 3b) and finally represented as

10 a synthetic diurnal fluctuation such as could be measured in the field (Fig. 3c). Our approach here is to demonstrate our analysis by comparison of calculation of hydroperiod using geometric methods (area under the sawtooth curve), the analytical solution, and a numerical approximation. The hydrograph in Fig. $3 \mathrm{c}$ is adapted from actual data presented by Hughes et al. (1998) for a tidal wetland in which a creek culvert restricts 15 flow and attenuates the second tidal peak.

\section{Method of analysis}

\subsection{Hydroperiod}

Quantitative hydrologic analysis commonly uses a hydrograph of total discharge $\left(L^{3} / T\right)$ vs. time to represent streamflow, and in such cases (with the appropriate time units), 20 the area under the curve given by the integral of the hydrograph function is understood to represent the total volume of flow $\left(L^{3}\right)$ over a given time period (Dingman, 2002). Similarly, we propose that the essential components (depth in units of length, duration in units of time) of the hydroperiod $\Omega$ of a location at any point $x$ in a wetland are appropriately quantified by the integral of the water level $(h)$ fluctuation function over

time, i.e. the area under the hydrograph curve:

$$
h=f(x, t) \text { so hydroperiod } \Omega(x) \equiv \int f(x, t) d t
$$

While we use Eq. (1) to represent hydroperiod for a wetland with a tidal period of $12 \mathrm{~h}$, and the appropriate units $(L \cdot T)$ for hydroperiod are $\mathrm{m} . \mathrm{h}$ in this case, a similar quantifi5 cation of hydroperiod could be used for any other, even non-tidal wetland, simply by using different time units (days, weeks, months etc.). One difficulty with this definition of hydroperiod is that the function describing the water level fluctuation in most wetlands is not known, even though the water levels can be measured over time. However, if $f(t)$ can be given by observed data at a particular location, numerical integration of water evel data over time $a$ to $b$ can easily be carried out in a spreadsheet (Simpson's Rule using a five-minute discretization of time is a convenient numerical method to compare with the analytical calculations here).

Using water depth in meters and time in hours, we next apply the above integration (results are given later) to the easily derivable equation that corresponds to the first part of the linear sawtooth pattern of water level fluctuation at point L1 (Fig. 2) represented in Fig. 3a. A similar analysis could be applied to any of the other points on the wetland profile (L2-L4). Taking into account the slope of the curve and the horizontal offset $(0.75 \mathrm{~h})$ due to the horizontal distance of $\mathrm{L} 1$ from the low tide mark, the equation is as follows:

$20 h=f(t)=\frac{1}{6} t-\frac{1}{8}$

The hydroperiod $\Omega$, as defined above, can therefore be expressed as the integral of Eq. (2) with respect to time. For the symmetrical sawtooth pattern, a piecewise integration of the part of the curve from time 0.75 to $6 \mathrm{~h}$ is sufficient to derive 0.25 of the total hydroperiod over $24 \mathrm{~h}$, as below:

$\left.\left.{ }_{25} \Omega(\mathrm{L} 1)=\int_{0.75}^{6} f(t) d t=\frac{1}{12} t^{2}\right]_{0.75}^{6}-\frac{1}{8} t\right]_{0.75}^{6}$ 
Similarly, for the sinusoidal tidal fluctuation curve presented in Fig. 3b, the function is of the form $h=u \sin v(t)+w$. The appropriate coefficients: $u$ is the amplitude (0.5), period is $2 \pi / v=12 \mathrm{~h}$, and $w$ controls the vertical translation (0.375) with a horizontal offset of $3 \mathrm{~h}$, give the following equation for the water level fluctuation at L1:

$5 h=f(t)=\frac{1}{2} \sin \frac{\pi}{6}(t-3)+\frac{3}{8}$

In this case, the hydroperiod $\Omega$ for the point $L 1$ in the wetland is the integral with respect to time of Eq. (4). In order to restrict the calculation to the area between the $x$-axis and the curve, we take the limits $a$ and $b$ of integration to be 1.4 and $10.6 \mathrm{~h}$, respectively, the approximate roots of the function for $h=0$. The resulting equation describing the 10 hydroperiod over $12 \mathrm{~h}$ (needs to be multiplied by 2 for the total daily hydroperiod) is as follows

$\left.\left.\Omega(\mathrm{L} 1)=\int_{1.4}^{10.6} f(t) d t=-\frac{3}{\pi} \cos \frac{\pi}{6}(t-3)\right]_{1.4}^{10.6}+\frac{3}{8} t\right]_{1.4}^{10.6}$

Finally, for the synthetic and most realistic hydrograph, presented in Fig. 3c, the function describing the water level variation over time is unknown. The most expedient analysis

15 for most such field data describing tidal fluctuations is to calculate the integral numerically. Similar analysis could be applied to obtain the hydroperiod for the other locations, or indeed any location along the profile of the wetland conceptual model simply by an appropriate vertical translation of the hydrograph curve. The complete hydrograph can be measured at the lowest point of the wetland coinciding with the low-tide mark, and because of the constant wetland mean bed slope, predicted hydrographs at all other higher elevations can be derived by subtracting the elevation of the location desired from the water levels of the complete hydrograph. Results from analysis of the three types of hydrograph curve in Fig. 3 at each of the four wetland locations are presented in Table 1.

\subsection{Hydraulic loading}

Reduction in contaminants in water flowing through a wetland is a function of hydraulic loading as discussed below. Hydraulic loading is easily defined in a flow-through treatment wetland, where the total influx $Q$ of wastewater to be treated is conveyed through

5 a control structure and the total wetted area $A$ of the wetland is well known, often held constant. In such cases, the hydraulic loading is defined as $q=Q / A$ (Kadlec and Knight, 1996; Kadlec and Wallace, 2008). However, in riverine or tidal wetlands where the water flow is bidirectional (or natural wetlands with groundwater inflow), and control structures are not common, hydraulic loading is more difficult to assess. The various

10 methods that have been used to quantify surface water flows in wetlands generally involve the Manning's equation. Kadlec and Knight (1996) present an empirical generalized friction equation, based on the Manning's formulation, to predict discharge $Q$ $\left(\mathrm{m}^{3} / \mathrm{d}\right)$ through wetlands of the form:

$Q=a W h^{b} S^{c}$

15 where $a$ is $1 \times 10^{7} \mathrm{~m}^{-1} \mathrm{~d}^{-1}$ to $5 \times 10^{7} \mathrm{~m}^{-1} \mathrm{~d}^{-1}$ with decreased vegetation density, $W$ is the width of the wetland $(\mathrm{m})$ perpendicular to flow, $h$ is the water depth $(\mathrm{m})$ with a recommended value of 3.0 for the exponent $b, S$ is the water surface slope in the direction of flow with an exponent $c$ value of 1.0.

The static form of this friction equation is not very useful for predicting either flow or

20 hydraulic loading in a tidal wetland because both water depth $h$ and wetted length in the direction of flow are continuously changing as a function of time and location $f(x, t)$ as the tide advances and recedes. Therefore, a hydraulic loading $q=Q / A$ is different from time to time and from location to location. Furthermore, the flux of water into and out of the tidal wetland is not driven primarily by the water surface slope $S$, but by the 25 vertical rise (inundation) and fall (drainage) of water levels due to the tides. In such cases, water surface slope $S$ is likely to be insignificantly small.

In order to account for dynamic properties of tidal hydraulic loading, first, we use the simple model shown in Fig. 2 to calculate an expression for local hydraulic loading with 
respect to distance inland, and then we extend this formulation to the general situation over time and over the entire wetland profile. The model shown in Fig. 2 is associated with the assumptions below:

1. One-dimensional flow over a constant mean slope $(\theta)$ with unit width $W$ $(=1)$ is assumed, and the wetted length $\ell$ is equally divided into $n$ intervals, $\Delta X=b=$ constant, and $n b=\ell$.

2. This mean wetland slope $\theta$ is represented by a system of terraces such that as the tidal level reaches those elevations, the terraces are immediately flooded or drained over their entire dimension $\Delta X$, and $\Delta X$ can be as large or small (many terraces) as desired.

3. The time over which total hydraulic loading is considered is $24 \mathrm{~h}$, the approximate length of the diurnal tidal cycle.

4. The water slope $S$ in the direction of flow is assumed to be very small and constant at $1 \times 10^{-6}$.

15 A local hydraulic loading over the $i$ th interval of dimension $\Delta X$ is defined as

$q_{i} \equiv \frac{Q_{i}}{A_{i}}=\frac{\alpha W_{i} \bar{h}_{i}^{3}}{\Delta X W_{i}}=\frac{\alpha \bar{h}_{i}^{3}}{\Delta X}, \quad i=0,1,2, \ldots, n-1$

where $Q_{i}$ is a local discharge over the $i$ th interval with an area $A_{i}\left(=\Delta X W_{i}\right), \alpha=a|S|$ for small $S$ in Eq. (6) by taking $c$ as 1 , and $\bar{h}_{i}$ is mean water depth for the $i$ th interval. For small intervals $\Delta X$, the mean water depth reduction $\Delta h$ in the upland direction over the $i$ th interval (Fig. 2) can be obtained by

$\Delta h=\Delta X \tan \theta=b \tan \theta$

If water height $h_{0}$ is given with reference to absolute low tide datum, the water depth $h_{i}$ at any interval can be represented as follows:

$h_{1}=h_{0}-\Delta h$

$$
\begin{aligned}
& h_{2}=h_{1}-\Delta h=h_{0}-2 \Delta h \\
& h_{3}=h_{0}-3 \Delta h \\
& \ldots \\
& h_{i}=h_{0}-i \Delta h
\end{aligned}
$$

5 Combining Eqs. (8) and (9), the mean water depth of the $i$ th interval at a particular time is given by

$\bar{h}_{i}=\frac{h_{i}+h_{i+1}}{2}=h_{0}-\left(i+\frac{1}{2}\right) b \tan \theta, \quad i=0,1,2, \ldots, n-1$.

Thus, local hydraulic loading at each interval of dimension $\Delta X$ can be represented by

$q_{i}=\frac{\alpha\left\lfloor h_{0}-(i+0.5) b \tan \theta\right\rfloor^{3}}{b}, \quad i=0,1,2, \ldots, n-1$.

10 Given the model with constant mean bedslope represented in Fig. 2, Eqs. (7-11) are a generalization of the calculation of a local hydraulic loading. Actually, Eq. (11) is valid in the general situation even if the interval $\Delta X$ is not treated as constant and mean water depth $\bar{h}_{i}$ is determined by

$\bar{h}_{i}=\frac{1}{\Delta X} \frac{1}{\Delta T} \int_{x_{i}}^{x_{i+1}} \int_{0}^{\Delta T} h(x, t) d x d t, \quad i=0,1,2, \ldots, n-1$.

15 where interval $\Delta X$ and angle of the slope are not necessarily constant, $\Delta T$ is total time period that an ith interval is submerged, and $h(x, t)$ is instantaneous water depth that is a function of time and location. In practice, the water depth variation $h(t)$ at any elevation $z$ corresponding to a terrace of dimension $\Delta X$ can be measured, and the mean water depth over time can be estimated with respect to the hydroperiod $\Omega(x)$ defined earlier (Eq. 1):

$\bar{h}_{i}=\frac{1}{T_{i}} \int_{0}^{T_{i}} h_{i} d t=\frac{1}{T_{i}} \Omega_{i}$ 
where $T_{i}$ is the time interval of submergence at the particular location where the hydroperiod is measured. The resulting mean water depth can be substituted for the term in the brackets in Eq. (11) to obtain the hydraulic loading for the wetted length $\Delta X$ corresponding to the particular terrace at that elevation.

$5 \quad$ Finally, the bulk hydraulic loading $q$ over the entire wetland length can be obtained by the weighted average local hydraulic loading over different intervals or terraces:

$q=\frac{\sum_{i=0}^{N-1} q_{i} \Delta X_{i} T_{i}}{\sum_{i=0}^{N-1} \Delta X_{i} T_{i}}$,

where $\Delta X_{i}$ is the ith interval length, and $T_{i}$ is the total time of submergence of the ith interval within a day. $T_{i}$ is an aspect of the hydroperiod that can be easily obtained 10 from examination of hydrographs at different elevations or locations in the wetland (Fig. $3 a-c)$. In the case that the interval width is constant, i.e. $\Delta X_{i}=$ constant, Eq. (14) is reduced to

$q=\frac{\sum_{i=0}^{N-1} q_{i} T_{i}}{\sum_{i=0}^{N-1} T_{i}}$.

For the purpose of this analysis, we demonstrate the method by applying these equa15 tions to the wetland conceptual model that we have described (Fig. 2). As before, for simplicity, we assume that the wetland length is divided into four terraces, one at the elevation of each of those points. Equivalently, for a pre-existing wetland with any number of well-defined terraces at different elevations, Eq. (14) could be used to compute the total hydraulic loading for the entire intertidal wetland length. We apply Eqs. (13)

20 and (14) to the three cases of hydrograph discussed previously to obtain estimates of mean water depth and loading for each of the wetland terraces. Results for the terrace elevations at points L1, L2, L3 and L4, as well as the total computed hydraulic loading for the wetland profile, are presented in Table 2.

603

\subsection{Wetland treatment capacity}

The ability of wetlands (Kadlec and Knight, 1996) and pond-wetland systems (Kadlec, 2003) to remove contaminants from wastewater and thereby improve water quality has been widely demonstrated. While the evidence for this is derived from water analyses 5 before and after transit through treatment wetlands, it is useful to be able to predict such performance in the process of wetland design. Performance data for numerous treatment wetlands have been compiled (Waterman and Brown, 1994) and analyzed by Kadlec and Knight (1996), who described a first-order $k-C^{*}$ model for estimating wetland contaminant uptake. For an areally-based formulation, this presumes the following 10 rate equation:

$J=k\left(C-C^{*}\right)$

where $C$ is the concentration $(\mathrm{mg} / \mathrm{L}), C^{*}$ is the background concentration $(\mathrm{mg} / \mathrm{L}), J$ the removal rate $\left(\mathrm{mg} / \mathrm{m}^{2} / \mathrm{d}\right)$ and $k$ the removal rate constant $(\mathrm{m} / \mathrm{d})$. The assumption of steady-state and constant flow $(P-E T=0)$, often used for design considerations, leads 15 to the exponential model of contaminant reduction:

$\frac{\left(C_{o}-C^{*}\right)}{\left(C_{i}-C^{*}\right)}=\exp \left(-\frac{k}{q}\right)$

where $C_{o}$ and $C_{i}$ are the outlet and inlet concentrations $(\mathrm{mg} / \mathrm{L})$, respectively, and $q$ is the hydraulic loading $(\mathrm{m} / \mathrm{d})$.

This model is recognized as empirical and very simple, but is merely used to show how different hydraulic loading and hydroperiod can affect treatment effectiveness. Although a slightly more complex first-order method - the $P-k-C^{*}$ model - has recently been introduced by Kadlec and Wallace (2008), it also depends on hydraulic loading $q$ or water depth $h$. For generalized estimates of mean performance of planned wetlands, the state of treatment technology does not yet support much more sophisticated models. Some of the limitations of the model used here include a dependence of rate 
constants on spatial vegetation variability, hydraulic loading and inlet concentrations (Kadlec, 2000), however further analysis of these factors is not considered here. The first-order $k-C^{*}$ model is applicable to the reduction of many types of water contaminants (Kadlec and Knight, 1996), and is used here to show the potential for tidal treat-

5 ment wetland design following the methods in this work. Bacteriological contamination remains a serious problem in parts of the New York-New Jersey Harbor Estuary, as described earlier, and constructed wetland systems have been shown to be particularly effective for removal of pathogenic bacteria (Arias et al., 2003).

\section{Results and discussion}

$10 \quad 4.1$ Hydroperiod spatial variation

The results of the above analyses for the three different hydrographs (Tables 1 and 2) are plotted in Fig. 4. Similar computations could be performed for points at any elevation along the wetland profile with any number of terraces, however the selected points L1-L4 provide an adequate basis for interpretation of the trends with distance.

15 The three hydrographs all result in a decreasing hydroperiod in a landward direction (Fig. 4a), as expected since water depths decrease with elevation in the wetland. The apparently exponential form of this trend is no doubt due to the bidirectional tidal flow originating at the seaward end, since the mean wetland bed-slope is constant here. This pattern provides a basis for estimating the flooding time and habitat suitability of

20 different elevations in the wetland for different vegetation species, as described below. It is interesting to note that the sinusoidal hydrograph (Fig. 3b) results in the greatest values of hydroperiod at each of the four locations, but that the linear sawtooth hydrograph (Fig. 3a) results in values within $1 \mathrm{~m} . \mathrm{h}$ of the values from the sinusoidal hydrograph, with the greatest discrepancy at points in the center of the wetland. The

25 hydroperiod at all four locations resulting from the synthetic field hydrograph (Fig. $3 \mathrm{c}$ ) shows a similar trend but the overall slope is considerably lower. The increased flood-

605

ing time due to the extended hydrograph recession evidently does not compensate for the reduced peak in water depth during the second tidal cycle in the $24 \mathrm{~h}$ period. Another factor explaining this pattern is that the upper part of the wetland (L3, L4) does not experience a diurnal flooding cycle because of the obstructed flow causing the modified hydrograph.

\subsection{Water depths and flooding time}

The maximum water depth (Table 3) at each of the wetland locations is identical for each hydrograph because of the geometry of the wetland conceptual model. However, the daily flooding time or duration, given by the time between the $x$-intercepts (Fig. 3), differs between hydrographs (Table 3 ), which accounts for the differing hydroperiod (Table 1). There is not a simple relationship among the hydroperiod, the maximum depths and the flooding time for the hydrographs, other than in the case of the simplified linear sawtooth hydrograph. Therefore, given the linear sawtooth hydroperiods intermediate between those for the ideal sinusoidal tidal hydrograph and the synthetic hydrograph,

15 a first-order value of the hydroperiod could be estimated assuming a linear sawtooth hydrograph if only the tidal peak timing and maximum depth were known. It is interesting to note that the synthetic field hydrograph has a longer daily flood time (Table 3) at the lowest point (L1) in the wetland than the sinusoidal hydrograph because of the longer tidal recession, despite the very asymmetrical tidal peak depths. Also, the sinu20 soidal hydrograph has the longest daily flood time for the highest point in the wetland (L4), in part because that location is only flooded half as often with the synthetic field hydrograph.

Information on maximum water depth and daily flooding time are critical to wetland restoration or design because it determines what types of vegetation are likely to be suited to different elevations along the wetland profile. Kadlec and Knight (1996) tabulate tolerance ranges of these factors for different types of wetland vegetation. Typical zonation of saltmarsh vegetation in the northern Atlantic coastal region (Carlisle et al., 2002; Mitsch and Gosselink, 2000; Bertness, 1999) is differentiated into upland, high 
marsh and low marsh habitats according to elevation. While most of the area in the wetland conceptual model considered here would be low marsh (more than one submergence per day) depending on the definition of high tide, asymmetrical hydrographs like the ones given in Fig. $3 \mathrm{c}$ are common in disturbed urban settings and introduce 5 additional variability.

Typical vegetation of salt and brackish marshes in Atlantic coastal settings from high to low elevations includes marsh elder (Iva frutescens), black rush (Juncus gerardi), marsh hay (Spartina patens), spikegrass (Distichlis spicata), and smooth cordgrass (Spartina alterniflora) (Thayer et al., 2005; Holst et al., 2003; Carlisle et al., 2002;

10 Mitsch and Gosselink, 2000; Bertness, 1999). Other less desirable species include cattail (Typha latifolia) and common reed (Phragmites spp.), however these are commonly used in treatment wetlands, especially outside North America (Song et al., 2006; Cooper, 2005; Kadlec and Knight, 1996). Maximum water depth and daily flooding time data such as that given in Table 3 might be used to justify construction of terraces at

15 different elevations designed as habitat for particular plant species. Such landscaping and the creation of habitat edges has also been found to be beneficial for fisheries production (Feagin and $\mathrm{Wu}, 2006$ ). For example, location L1 has the maximum water depths and longest daily flood times, and would provide the best habitat for floating or submerged aquatic vegetation (SAV). Saline or brackish marshes generally lack the dense SAV found in freshwater environments (Yozzo and Smith, 1998), but perhaps with improving water quality in the New York-New Jersey Harbor Estuary, species such as eelgrass (Zostera marina) could eventually be introduced in this area. Zones of cattail or cordgrass are better suited to elevations near L2, but black rush could be planned for a zone above L3 because this latter species tolerates a maximum water depth only up to $0.25 \mathrm{~m}$ (Kadlec and Knight, 1996). Other considerations such as lower salinity, soil sulfide (Chambers et al., 2003) and a desire to avoid invasive species might favor or preclude the use of common reed (Phragmites spp.) in selecting appropriate vegetation for different coastal wetland settings according to hydroperiod characteristics.

607

\subsection{Wetland treatment effectiveness}

Hydraulic loading also varies with distance and elevation from the low tide mark (Fig. 4b). Hydraulic loading increases apparently exponentially from high to low elevations in the wetland for the sinusoidal and linear sawtooth hydrographs considered

5 here, but the rate of increase is much lower and appears to decrease towards the lowest elevation in the case of the synthetic field hydrograph. Highest hydraulic loading values occur with the sinusoidal hydrograph and the lowest values occur with the synthetic field hydrograph, with intermediate linear sawtooth hydrograph values. The patterns in Fig. 4a and b suggest that, as with the hydroperiod, in the absence of de-

10 tailed information on the shape of the hydrograph, estimating hydraulic loading based on a linear sawtooth pattern with maximum water depths would be a good first-order approach. In wetlands with sparse vegetation, hydraulic loading would be higher by a factor of 5 , based on the friction equation (Eq. 6), but values calculated here (Table 2) are consistent with typical values of surface treatment wetland hydraulic loading 15 rates (Kadlec and Knight, 1996; Sun et al., 2006). Modern vertical flow subsurface wetland treatment systems have been successfully operated at hydraulic loading rates over $0.4 \mathrm{~m} / \mathrm{d}$ with recirculation (Zhao et al., 2004), and even $>1 \mathrm{~m} / \mathrm{d}$ for experimental vertical flow systems (Arias et al., 2003) and tidal systems with special gravel media arrangement (Sun et al., 2007).

20 Hydraulic loading values (Table 2) for locations at different elevations in a tidal treatment wetland design are useful because they may be used with Eq. (17) to predict possible treatment effectiveness for various water quality parameters. Wetland elevation landscaping may then be optimized (larger area at certain elevation(s)) to maximize treatment effectiveness (often expressed as \% reduction) for a given vegetation habitat

25 selection (Table 3). In an urbanized coastal setting like in New York City, a major water quality concern is fecal coliform contamination from CSO discharges, as discussed earlier. Here, we show how, given a particular type of hydrograph, and resulting hydroperiod and hydraulic loading, predictions can be made for possible fecal coliform 
reduction that could be expected for constructed or restored wetlands along the margin of Flushing Bay, for example. We assume that based on available data, an initial concentration $C_{i}$ of fecal coliform contamination in coastal waters that enters a proposed tidal treatment wetland is $10000 \mathrm{CFU} / 100 \mathrm{~mL}$, and a reasonable background

5 concentration $C^{*}$ is $500 \mathrm{CFU} / 100 \mathrm{~mL}$. A conservative rate constant $k$ of $0.20 \mathrm{~m} / \mathrm{d}$ for fecal coliform contamination reduction is assumed based on a tabulation of available data by Kadlec and Knight (1996), however considerably higher rate constants have been reported more recently for higher initial pathogenic bacterial concentrations $\left(C_{i}\right)$ and mass loading rates (Arias et al., 2003).

10 Results of calculations based on Eq. (17) for different hydraulic loadings at different elevations for different hydrographs are presented in Table 4. Overall effectiveness of a particular wetland design would depend on the relative area at different elevations and the vegetation density. The data values shown indicate that at high vegetation densities, the estimated percent reduction of fecal coliform contamination equals $95 \%$

15 for the two highest terraces (L3, L4) with all three hydrographs considered in this work. Somewhat lower percent reductions are seen at lower elevations (L1, L2), with the lowest values (55\% and $82 \%)$ for the sinusoidal hydrograph. Overall percent reductions calculated for the weighted mean hydraulic loading over the entire intertidal length range from $77 \%$ for the sinusoidal hydrograph to $94 \%$ for the synthetic field hydrograph.

20 At low vegetation densities, percent reductions are very low at the lowest elevation (L1), ranging from only $15 \%$ for the sinusoidal hydrograph to $48 \%$ for the synthetic field hydrograph, and extend up to $95 \%$ at the highest elevation (L4) for all three hydrographs. Overall percent reduction values for the entire intertidal length range from $27 \%$ for the sinusoidal hydrograph to $57 \%$ for the synthetic field hydrograph. This shows that even

25 if vegetation establishment is not ideal, especially in early stages of development of treatment wetlands, there is still a considerable benefit for water quality improvement that can be expected. Contaminant removal effectiveness increases at higher elevations with smaller hydroperiods (Table 1) and lower hydraulic loading (Table 2). This suggests that the types of analyses presented above would be useful in selecting ele-

609

vations optimized for the establishment of different species, and terraces constructed at these elevations would maximize treatment effectiveness. One strategy might be to build up the lowest elevations in the profile to reduce the largest hydroperiods and facilitate plant colonization. Similar calculations could be made for other water quality 5 parameters using appropriate rate constants in Eq. (17).

\subsection{Comparison to other settings}

The tidal wetland conceptual model presented in Figs. 2 and 3 provides the basis for design and restoration in similar settings where the tidal range can be similarly scaled and an approximate bedslope can be identified. The prediction of wetlands hydroperiod

10 is important for design decisions about the types of wetlands vegetation to be planted or restored in different locations and for the residence time of water to be treated in the wetland. The hydraulic loading is important to predict the effectiveness of the proposed wetland restoration or design on improvement of water quality in the adjacent coastal waters. Hydraulic loading is commonly used in the one-dimensional, stationary first 15 order areal model described above (Eq. 17). The assumptions underlying this model, as listed by Kadlec and Knight (1996), are generally adequately met for coastal tidal wetlands since the tidal cycle can be considered a dynamic steady state loading to a first approximation. A possible exception here is the assumption of no backmixing or bypassing, as discussed below.

20 Constraining the model to one-dimensional tidal flow perpendicular to the shoreline and assuming uniform wetland properties in the lateral directions are necessary simplifications for this analysis. In reality, some component of lateral flow is inevitable due to the heterogeneity of wetland ecosystems, so caution in applying this type of analysis is warranted in areas along narrow creeks with strong tidal flow, for example. How-

25 ever, the net effect of additional lateral flow is that flowpaths and hydraulic residence times are lengthened which would enhance the tidal wetland treatment processes. So, the consequence of restricting our conceptual model to one-dimensional flow is that our analysis likely underestimates the probable water quality improvement that can be 
anticipated in these systems.

Backmixing and bypassing are not necessarily limitations for this analysis for two reasons. Backmixing is inherent in tidal flows and the effects of such recirculation have been recognized to enhance treatment effectiveness (Zhao et al., 2004), so the reduc-

5 tions predicted by the first-order areal model may be conservative in these settings. Secondly, it has been recognized that bypassing due to non-ideal flow and the formation of preferential flowpaths are common in all constructed wetlands, resulting in a need for new paradigms (Kadlec, 2000). Our analysis shares this non-ideal-flow reality with conventional first-order areal model analyses, which nevertheless adequately

10 describe the bulk of wetlands performance data (Kadlec and Knight, 1996; Waterman and Brown, 1994). However, the effects of backmixing due to tidal flow could be added to the analysis presented here by quantifying a return-flow factor incorporated in a simple mixing model of new coastal water and recirculated tidal flow (Dilorenzo et al., 1994).

15 While the water quality improvement function of coastal wetlands is well known - wetlands as "Nature's kidneys" (Mitsch and Gosselink, 2007), quantification of predicted treatment capacity is useful to promote restoration of these tidal habitats. The methods and analysis proposed here are intended for design and/or restoration of coastal wetlands where the principal inflow is the tidal fluctuation, however it is interesting to 20 distinguish these results from typical analyses in non-tidal flow-through treatment wetlands (Kadlec and Knight, 1996). The expression for mean water depth $h_{i}$ and local hydraulic loading $q_{i}$ quantified by Eqs. (10) and (11), respectively, are only applicable to wetlands with a bottom slope $\theta>0$ otherwise the calculation of local hydraulic loading would evaluate to zero. There is a fundamental difference between the analysis presented here, in terms of variations of water levels $h$ with time or hydraulic loading $q$ at a single elevation on a profile, and the usual formulation of water levels in treatment wetlands as profiles with distance at a particular time or steady-state design conditions. In this latter approach, the wetland inflow $Q$, the wetted area $A$ and hence the hydraulic loading $q$ are considered constant (at least for "normal" design operation),

whereas they are variable over time and space in the tidal wetland setting described here. In addition, controlled water levels in flow-through treatment wetlands are often maintained more or less constant. Under these circumstances, hydroperiod $\Omega(x)$ can be usefully quantified using Eq. (1) for different points in the wetland, however it would 5 not be useful to quantify hydraulic loading using Eq. (11), because of the general waterlevel time-invariance under design conditions. We note however that one advantage of our approach is that it is simpler to measure time changes at a point rather than simultaneous water levels at many locations.

\section{Conclusions and implications}

10 We have presented a new method to quantify hydroperiod and hydraulic loading that is particularly well suited to evaluating tidal wetland designs for the purpose of urban coastal water quality improvement. To illustrate an application of this method, we described a conceptual model for tidal wetland design for which we evaluated three different types of diurnal water level fluctuation: a simplified linear sawtooth hydrograph,

15 a sinusoidal hydrograph and a synthetic asymmetrical hydrograph patterned after actual field data from a tidal wetland with disturbed hydrology. Our approach was to derive expressions for hydroperiod and hydraulic loading for any location along a wetland elevation profile with a constant mean slope, building on a friction equation for surface water flow (Kadlec and Knight, 1996; Kadlec and Wallace, 2008). These expressions reflect the adaptation of analyses for static flow-through wetlands systems to the dynamic tidal environment, where water levels and wetted areas are constantly changing over time, complicating the prediction of treatment effectiveness. We then demonstrated how tidal water-level fluctuations at different elevations in our conceptual model can be used in assessing aspects of hydroperiod such as maximum depth and daily 25 flood time in order to select plant species that are best suited to those wetland habitats. Such information can also be used to guide landscaping of restored and constructed tidal wetlands in coastal settings to optimize relative areas of the wetland graded to 
different elevations for maximum treatment effectiveness. Finally, we showed, using a first order model for contaminant reduction in wetlands (Kadlec and Knight, 1996; Kadlec, 2000), how such hydrograph interpretation can be used to assess potential reductions in fecal coliform contamination in water flowing back and forth through the tidal wetland.

Many large urban coastal areas suffer from poor water quality due to non-point source runoff, wastewater treatment and combined sewer overflow (CSO) discharges, including New York City. However, despite the historical losses of most coastal wetlands in urban areas, the increasing recognition of the functions and values of tidal

10 wetlands for water quality improvement and treatment (the developing science of ecohydrology) has stimulated the protection and restoration of these endangered habitats. Our work provides a way to apply the concept of hydraulic loading and hydrograph analysis to evaluate the effectiveness of these ecosystems for water quality improvement, and promote their restoration and construction for that purpose. Results presented

15 here suggest that, given the great need for additional treatment of impaired coastal waters, restoration and construction of tidal wetlands in urban areas remains an underexploited opportunity for improving adjacent water quality.

\section{References}

Arias, C. A., Cabello, A., Brix, H., and Johansen, N. H.: Removal of indicator bacteria from municipal wastewater in an experimental two-stage vertical flow constructed wetland system, Water Sci. Technol., 48, 35-41, 2003.

Bertness, M. D.: The Ecology of Atlantic Shorelines, Sinauer Associates, Inc., Sunderland, MA, 417 pp., 1999.

Boswell, J. S., and Olyphant, G. A.: Modeling the hydrologic response of groundwater dominated wetlands to transient boundary conditions: implications for wetland restoration, $\mathrm{J}$. Hydrol., 332, 467-476, 2007.

Carlisle, B. K., Donovan, A. M., Hicks, A. L., Kooken, V. S., Smith, J. P., and Wilbur, A. R.:

A volunteer's handbook for monitoring New England salt marshes, Massachusetts Office of Coastal Zone Management, Boston, MA, 2002.

Chambers, R. M., Osgood, D. T., Bart, D. J., and Montalto, F.: Phragmites australis invasion and expansion in tidal wetlands: interactions among salinity, sulfide, and hydrology, Estuaries, 26, 398-406, 2003.

Cooper, P.: The performance of vertical flow constructed wetland systems with special reference to the significance of oxygen transfer and hydraulic loading rates, Water Sci. Technol., 51, 81-90, 2005.

Dahl, T. E.: Status and trends of wetlands in the conterminous United States 1998-2004, US

10 Department of the Interior; Fish and Wildlife Service, Washington DC, 116 p., 2006.

Dilorenzo, J. L., Ram, R. V., Huang, P. S., and Najarian, T. O.: Pollution Susceptibility of WellMixed Tidal Basins, J. Waterway Port Coastal and Ocean Engineering-ASCE, 120(4), 404422, 1994.

Dingman, S. L.: Physical Hydrology, Prentice-Hall Inc., Upper Saddle River, NJ, 646 pp., 2002.

Eaton, T. T.: Analytical estimates of hydraulic parameters for an urbanized estuary - Flushing Bay, J. Hydrol., 347, 188-196, 2007.

Feagin, R. A. and Wu, X. B.: Spatial pattern and edge characteristics in restored terrace versus reference salt marshes in Galveston Bay, Wetlands, 26, 1004-1011, 2006.

Fugate, D. and Chant, B.: Aggregate settling velocity of combined sewage overflow, Mar. Pollut. Bull., 52, 427-432, 2006.

Garcia-Barcina, J. M., Gonzalez-Oreja, J. A., and De la Sota, A.: Assessing the improvement of the Bilbao estuary water quality in response to pollution abatement measures, Water Res., 40, 951-960, 2006.

Grant, S. B., Sanders, B. F., Boehm, A. B., Redman, J. A., Kim, J. H., Mrse, R. D., Chu, A. K.,

25 Gouldin, M., McGee, C. D., Gardiner, N. A., Jones, B. H., Svejkovsky, J., and Leipzig, G. V.: Generation of enterococci bacteria in a coastal saltwater marsh and its impact on surf zone water quality, Environ. Sci. Technol., 35, 2407-2416, 2001.

Havens, K. J., Varnell, L. M., and Watts, B. D.: Maturation of a constructed tidal marsh relative to two natural reference tidal marshes over 12 years, Ecol. Eng., 18, 305-315, 2002.

30 Holst, L., Rozsa, R., Benoit, L., Jacobson, S., and Rilling, C.: Long Island Sound Habitat Restoration Initiative: Technical Support for Coastal Habitat Restoration, USEPA Long Island Sound Study Habitat Restoration Work Group, Stamford, CT, 2003.

Hughes, C. E., Binning, P., and Willgoose, G. R.: Characterisation of the hydrology of an estu- 
arine wetland, J. Hydrol., 211, 34-49, 1998.

Hunt, R. J., Walker, J. F., and Krabbenhoft, D. P.: Characterizing hydrology and the importance of ground-water discharge in natural and constructed wetlands, Wetlands, 19, 458-472, 1999.

5 Jeng, H. A. C., Englande, A. J., Bakeer, R. M., and Bradford, H. B.: Impact of urban stormwater runoff on estuarine environmental quality, Estuar. Coast. Shelf S., 63, 513-526, 2005.

Kadlec, R. H.: The inadequacy of first-order treatment wetland models, Ecol. Eng., 15, 105$119,2000$.

Kadlec, R. H.: Pond and wetland treatment, Water Sci. Technol., 48, 1-8, 2003.

10 Kadlec, R. H. and Knight, R. L.: Treatment Wetlands, CRC Press, Boca Raton, LA, 893 pp., 1996.

Kadlec, R. H. and Wallace, S. D.: Treatment Wetlands, 2nd edn., CRC Press, Boca Raton, London, New York, 1016 pp., 2008.

Kadlec, R. H. and Watson, J. T.: Hydraulics and solids accumulation in a gravel bed treatment

15 wetland, in: Constructed Wetlands for Water Quality Improvement, edited by: Moshiri, G. A., CRC Press, Boca Raton, LA, 1993.

Langergraber, G., Haberl, R., Laber, J., and Pressl, A.: Evaluation of substrate clogging processes in vertical flow constructed wetlands, Water Sci. Technol., 48, 25-34, 2003.

Li, H. L., Li, L., and Lockington, D.: Aeration for plant root respiration in a tidal marsh, Water Resour. Res., 41, 2005.

Long, K. S. and Nestler, J. M.: Hydroperiod changes as clues to impacts on Cache River Riparian Wetlands, Wetlands, 16, 379-396, 1996.

Marani, M., Lanzoni, S., Zandolin, D., Seminara, G., and Rinaldo, A.: Tidal meanders, Water Resour. Res., 38, 2002.

25 Marani, M., Belluco, E., D’Alpaos, A., Defina, A., Lanzoni, S., and Rinaldo, A.: On the drainage density of tidal networks, Water Resour. Res., 39, 2003.

Mitsch, W. M. and Gosselink, J. G.: Wetlands, 3rd edn., John Wiley and Sons, Inc., New York, 2000.

Mitsch, W. M. and Gosselink, J. G.: Wetlands, 4th edn., John Wiley and Sons, Inc., Hoboken, NJ, 582 pp., 2007.

Montalto, F. A. and Steenhuis, T. S.: The link between hydrology and restoration of tidal marshes in the New York New Jersey Estuary, Wetlands, 24, 414-425, 2004.

Nuttle, W. K.: Measurement of wetland hydroperiod using harmonic analysis, Wetlands, 17,

615

82-89, 1997.

NYCIBO: City's \$17 Billion Water \& Sewer Plan - Balancing Risks and Costs, New York City Independent Budget Office, May 2004, http://home.nyc.gov/html/records/pdf/govpub/ 1055 waterfiscalbrief.pdf, 2004.

5 NYCWTTF: Recommendations for the transfer of city-owned properties containing wetlands, NYC Wetlands Transfer Task Force, New York downloaded 30 January 2008 from http:// www.nycgovparks.org/sub_about/parks_divisions/nrg/wttf/index.html, 283, 2007.

Odum, W. E., Odum, E. P., and Odum, H. T.: Natures pulsing paradigm, Estuaries, 18, 547$555,1995$.

10 OEC: PlaNYC - A Greener, Greater New York, Mayor's Office of Operations, Office of Environmental Coordination, http://www.nyc.gov/html/planyc2030/html/home/home.shtml, access: 9 November 2007.

Simenstad, C., Tanner, C., Crandell, C., White, J., and Cordell, J.: Challenges of habitat restoration in a heavily urbanized estuary: Evaluating the investment, J. Coastal Res., 6-23, 2005.

15 Song, Z. W., Zheng, Z. P., Li, J., Sun, X. F., Han, X. Y., Wang, W., and Xu, M.: Seasonal and annual performance of a full-scale constructed wetland system for sewage treatment in China, Ecol. Eng., 26, 272-282, 2006.

Steinberg, N., Suszkowski, D. J., Clark, L., and Way, J.: Health of the Harbor: the first comprehensive look at the state of the NY/NJ Harbor estuary, Hudson River Foundation, New York, 86, 2004

Sun, G., Gray, K. R., and Biddlestone, A. J.: Treatment of agricultural wastewater in a pilot-scale tidal flow reed bed system, Environ. Technol., 20, 233-237, 1999a.

Sun, G., Gray, K. R., Biddlestone, A. J., and Cooper, D. J.: Treatment of agricultural wastewater in a combined tidal flow-downflow reed bed system, Water Sci. Technol., 40, 139-146, 1999b.

Sun, G., Gray, K. R., Biddlestone, A. J., Allen, S. J., and Cooper, D. J.: Effect of effluent recirculation on the performance of a reed bed system treating agricultural wastewater, Process. Biochem., 39, 351-357, 2003.

Sun, G., Zhao, Y., Allen, S., and Cooper, D.: Generating "tide" in pilot-scale constructed wetlands to enhance agricultural wastewater treatment, Eng. Life Sci., 6, 560-565, 2006.

Sun, G., Zhao, Y. Q., and Allen, S. J.: An alternative arrangement of gravel media in tidal flow reed beds treating pig farm wastewater, Water Air Soil Poll., 182, 13-19, 2007.

Thayer, G. W., McTigue, T. A., Salz, R. J., Merkey, D. H., Burrows, F. M., and Gayaldo, P. F. 
(Eds.): Science-based restoration monitoring of coastal habitats: tools for monitoring coastal habitats. NOAA Coastal Ocean Program Decision Analysis Series, 2(23), NOAA National Centers for Coastal Ocean Science, Silver Spring, MD, 628 pp., 2005.

Vokral, J., Gumb, D., Cavallaro, A. D., Mehrotra, S., and Rosenberg, E.: Wetlands at work, Civil $5 \quad$ Eng., 73, 56-63, 2003.

Waterman, J. D. and Brown, D. S.: Wetlands Treatment Database, Risk Reduction Engineering Laboratory, Cincinnati, OH, EPA/600/A-94/228, 1994.

Wolanski, E., Boorman, L. A., Chicharo, L., Langlois-Saliou, E., Lara, R., Plater, A. J., Uncles, R. J., and Zalewski, M.: Ecohydrology as a new tool for sustainable management of estuaries and coastal waters, Wetlands Ecol. Manag., 12, 235-276, 2004.

Xun, Z., Ruan, C. X., Yang, Y. Y., Bin, F., and Ou, Y. C.: Tidal effects of groundwater levels in the coastal aquifers near Beihai, China, Environ. Geol., 51, 517-525, 2006.

Yozzo, D. J. and Smith, D. E.: Composition and abundance of resident marsh-surface nekton: comparison between tidal freshwater and salt marshes in Virginia, USA, Hydrobiologia, 362, 15 9-19, 1998.

Zalewski, M.: Ecohydrology - the scientific background to use ecosystem properties as management tools toward sustainability of water resources, Ecol. Eng., 16, 1-8, 2000.

Zalewski, M.: Ecohydrology - the use of ecological and hydrological processes for sustainable management of water resources, Hydrolog. Sci. J, 47, 823-832, 2002.

20 Zedler, J. B. and Callaway, J. C.: Evaluating the progress of engineered tidal wetlands, Ecol. Eng., 15, 211-225, 2000.

Zeff, M. L.: Salt marsh tidal channel morphometry: Applications for wetland creation and restoration, Restor. Ecol., 7, 205-211, 1999.

Zhao, Y. Q., Sun, G., and Allen, S. J.: Purification capacity of a highly loaded laboratory scale tidal flow reed bed system with effluent recirculation, Sci. Total Environ., 330, 1-8, 2004.

Table 1. Values of hydroperiod $\Omega(\mathrm{m} . \mathrm{h})=\int h d t$ calculated using different methods for each of the wetland hydrographs in Fig. 3.

\begin{tabular}{lcccccc}
\hline & \multicolumn{3}{c}{ Linear sawtooth } & \multicolumn{2}{c}{ Sinusoidal } & Synthetic field data \\
Wetland & Geometric & Equation & Numerical & Equation & Numerical & Numerical \\
location & area & integration & integration & integration & integration & integration \\
\hline L1 & 9.2 & 9.2 & 9.2 & 9.5 & 9.5 & 6.3 \\
L2 & 4.7 & 4.7 & 4.7 & 5.4 & 5.4 & 2.8 \\
L3 & 1.7 & 1.7 & 1.7 & 2.4 & 2.4 & 1.1 \\
L4 & $1.9 \times 10^{-1}$ & $1.9 \times 10^{-1}$ & $1.9 \times 10^{-1}$ & $4.6 \times 10^{-1}$ & $4.6 \times 10^{-1}$ & $1.6 \times 10^{-1}$ \\
\hline
\end{tabular}


Table 2. Values of mean water depth $h_{i}(\mathrm{~m})$ and hydraulic loading $q_{i}(\mathrm{~m} / \mathrm{d})$ over $24 \mathrm{~h}$ calculated for each of the wetland hydrographs in Fig. 3 . Values for hydraulic loading $q_{i}$ of sparsely vegetated wetlands would be $5 \times$ greater (see Eq. 6 ).

\begin{tabular}{lccccccc}
\hline \multirow{2}{*}{ Parameter } & Location & \multicolumn{2}{c}{ Linear sawtooth } & \multicolumn{2}{c}{ Sinusoidal } & \multicolumn{2}{c}{ Synthetic field data } \\
& & $h_{i}$ & $q_{i}$ & $h_{i}$ & $q_{i}$ & $h_{i}$ & $q_{i}$ \\
\hline Densely & L1 & $4.4 \times 10^{-1}$ & $1.4 \times 10^{-1}$ & $5.2 \times 10^{-1}$ & $2.3 \times 10^{-1}$ & $3.2 \times 10^{-1}$ & $5.7 \times 10^{-2}$ \\
Vegetated & L2 & $3.2 \times 10^{-1}$ & $5.0 \times 10^{-2}$ & $3.9 \times 10^{-1}$ & $1.0 \times 10^{-1}$ & $2.9 \times 10^{-1}$ & $4.0 \times 10^{-2}$ \\
Wetland & L3 & $2.0 \times 10^{-1}$ & $1.3 \times 10^{-2}$ & $2.4 \times 10^{-1}$ & $2.0 \times 10^{-2}$ & $2.2 \times 10^{-1}$ & $1.8 \times 10^{-2}$ \\
$a=1 \times 10^{7} \mathrm{~m}^{-1} \mathrm{~d}^{-1}$ & L4 & $7.1 \times 10^{-2}$ & $5.9 \times 10^{-4}$ & $9.0 \times 10^{-2}$ & $1.0 \times 10^{-3}$ & $7.4 \times 10^{-2}$ & $6.7 \times 10^{-4}$ \\
& Entire & - & $8.0 \times 10^{-2}$ & - & $1.2 \times 10^{-1}$ & - & $4.4 \times 10^{-2}$ \\
\hline
\end{tabular}

Table 3. Aspects of hydroperiod critical to wetland vegetation habitats.

\begin{tabular}{cccccccc}
\hline $\begin{array}{c}\text { Wetland } \\
\text { location }\end{array}$ & $\begin{array}{c}\text { Max. } \\
\text { depth }(\mathrm{m})\end{array}$ & $\begin{array}{c}\text { Linear sawtooth } \\
\text { Daily flood } \\
\text { time }(\mathrm{h})\end{array}$ & $\begin{array}{c}\text { Daily flood } \\
\text { time }(\%)\end{array}$ & $\begin{array}{c}\text { Saily flood } \\
\text { time }(\mathrm{h})\end{array}$ & $\begin{array}{c}\text { Saily flood } \\
\text { time (\%) }\end{array}$ & $\begin{array}{c}\text { Syild field data } \\
\text { Dailood } \\
\text { time (h) }\end{array}$ & $\begin{array}{c}\text { Daily flood } \\
\text { time }(\%)\end{array}$ \\
\hline L1 & 0.875 & 21.0 & 87.5 & 18.3 & 76.3 & 19.4 & 80.8 \\
L2 & 0.625 & 14.7 & 61.2 & 13.7 & 57.1 & 9.7 & 40.4 \\
L3 & 0.375 & 8.7 & 36.1 & 10.0 & 41.7 & 5.0 & 20.8 \\
L4 & 0.125 & 2.7 & 11.2 & 5.3 & 22.1 & 2.2 & 9.2 \\
\hline
\end{tabular}


Table 4. Predicted tidal wetland effluent concentrations $C_{o}$ and reduction of fecal coliform bacteria (CFU/100 mL) depending on hydrograph type, hydraulic loading (Table 2) and wetland location. Constant values are an inflow concentration $C_{i}$ of $10000 \mathrm{CFU} / 100 \mathrm{~mL}$, background concentration $C^{*}$ of $500 \mathrm{CFU} / 100 \mathrm{~mL}$, and a rate constant $k$ of $0.20 \mathrm{~m} / \mathrm{d}$.

\begin{tabular}{|c|c|c|c|c|c|c|c|}
\hline \multirow[b]{2}{*}{ Comment: } & \multirow[b]{2}{*}{ Wetland location } & \multicolumn{2}{|c|}{ Linear sawtooth } & \multicolumn{2}{|c|}{ Sinusoidal } & \multicolumn{2}{|c|}{ Synthetic field data } \\
\hline & & $C_{o}$ & $\%$ reduction & $C_{o}$ & $\%$ reduction & $C_{o}$ & $\%$ reduction \\
\hline Densely & L1 & $2.8 \times 10^{3}$ & 72 & $4.5 \times 10^{3}$ & 55 & $7.8 \times 10^{2}$ & 92 \\
\hline vegetated & L2 & $6.7 \times 10^{2}$ & 93 & $1.8 \times 10^{3}$ & 82 & $5.6 \times 10^{2}$ & 94 \\
\hline wetland & L3 & $5.0 \times 10^{2}$ & 95 & $5.0 \times 10^{2}$ & 95 & $5.0 \times 10^{2}$ & 95 \\
\hline$a=1 \times 10^{7} \mathrm{~m}^{-1} \mathrm{~d}^{-1}$ & L4 & $5.0 \times 10^{2}$ & 95 & $5.0 \times 10^{2}$ & 95 & $5.0 \times 10^{2}$ & 95 \\
\hline Weighted mean & entire & $1.3 \times 10^{3}$ & 87 & $2.3 \times 10^{3}$ & 77 & $6.0 \times 10^{2}$ & 94 \\
\hline Sparsely & L1 & $7.6 \times 10^{3}$ & 24 & $8.5 \times 10^{3}$ & 15 & $5.2 \times 10^{3}$ & 48 \\
\hline vegetated & L2 & $4.8 \times 10^{3}$ & 52 & $6.9 \times 10^{3}$ & 31 & $4.0 \times 10^{3}$ & 60 \\
\hline wetland & L3 & $9.4 \times 10^{2}$ & 91 & $1.8 \times 10^{3}$ & 82 & $1.5 \times 10^{3}$ & 85 \\
\hline$a=5 \times 10^{7} \mathrm{~m}^{-1} \mathrm{~d}^{-1}$ & $\mathrm{~L} 4$ & $5.0 \times 10^{2}$ & 95 & $5.0 \times 10^{2}$ & 95 & $5.0 \times 10^{2}$ & 95 \\
\hline Weighted mean & entire & $6.3 \times 10^{3}$ & 37 & $7.3 \times 10^{3}$ & 27 & $4.3 \times 10^{3}$ & 57 \\
\hline
\end{tabular}

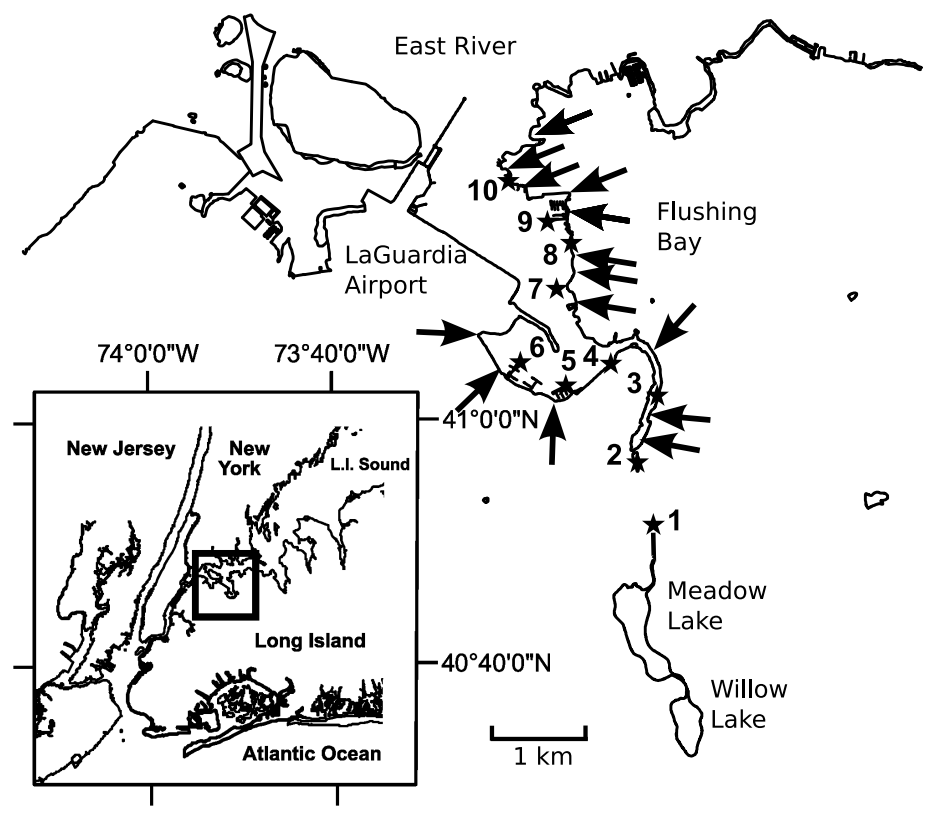

Fig. 1. Location map showing Flushing Bay and environs, an embayment of the NY-NJ Harbor Estuary with persistent poor water quality. Arrows show locations of combined sewage outfall (CSO) discharge points, and numbered stars are locations where total coliform samples were taken (Eaton, unpublished data), (figure reproduced with kind permission from Elsevier). 

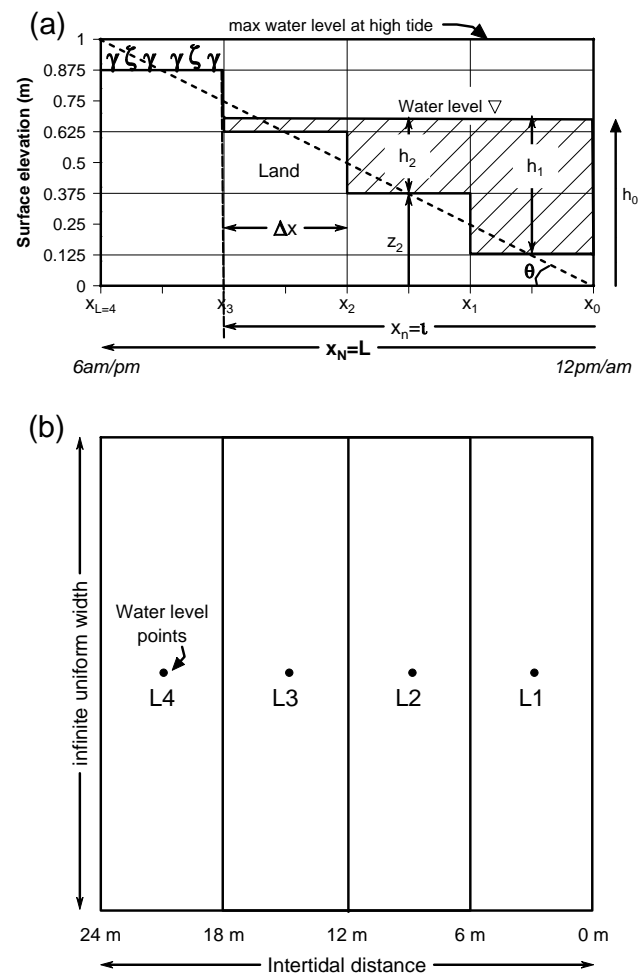

Fig. 2. Conceptual model for tidal wetland geometry: (a) Profile view: Elevation and profile length of terraces correspond to mean wetland bed slope $\theta$, and schematic vegetation shown only on upper terrace for clarity; (b) Plan view.
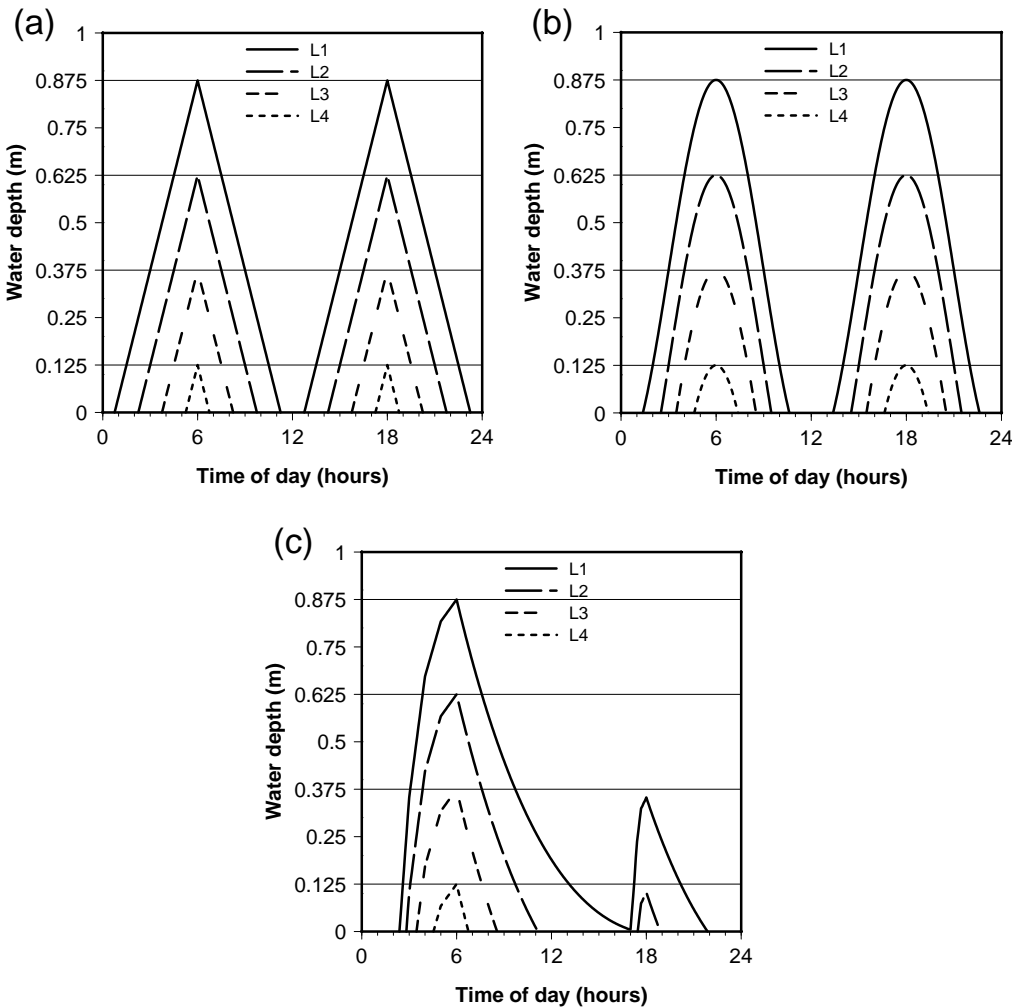

Fig. 3. Tidal water level variation at different points in conceptual model of wetland: (a) simplified linear sawtooth tidal variation, (b) sinusoidal tidal variation, and (c) realistic synthetic data adapted from Hughes et al. (1998). 

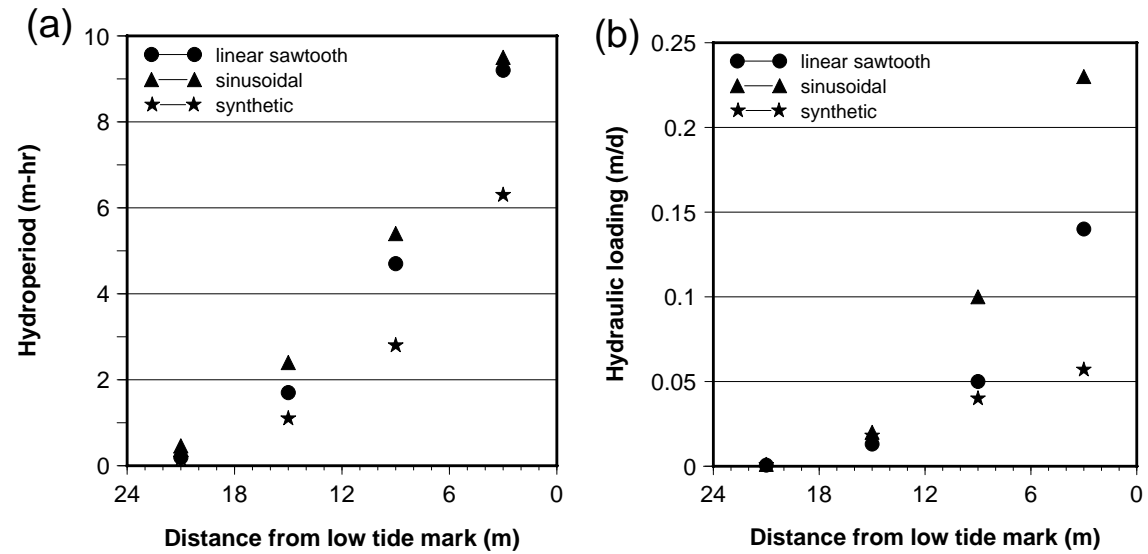

Fig. 4. Variation in calculated parameters for tidal wetland for three different hydrographs at each of the locations L1, L2, L3, and L4: (a) hydroperiod $\Omega$ (m.h); (b) hydraulic loading $q$ $(\mathrm{m} / \mathrm{d})$. The difference in distance from the low tidal mark along the slope and the horizontal axis is assumed to be negligible because of the small mean slope of the wetland profile. Values of hydraulic loading are calculated assuming a value of $a=1 \times 10^{7}$ corresponding to dense vegetation (Eq. 6). 